\title{
Instrument of determination and prediction of public opinion using IPTV statistic data
}

\author{
Vjačeslavs Dubovskis \\ Rezeknes Augstskola, Faculty of Engineering
}

\begin{abstract}
Recent tendencies show an increase of information pressure on Latvia. At the moment, Latvian political figures and government persons have recognized that the country takes a hybrid war. There is a need for a new instrument of determination and prediction of public opinion. The new instrument should allow: profiling audience by identification and prediction of the rate of dissemination of information, forecasting the depth of information, forecasting how public opinion is formed, identifying and previse the adoption of the reported information. The results of the work will create a tool that a variety of institutions will be able to apply it. These institutions may be television channels, government agencies, research organizations, and others. The tool will not only accurately determine the current picture of situation, but also with high accuracy to make forecasts about the state of public opinion.
\end{abstract}

Keywords: Digital multimedia broadcasting, Channel Popularity, IPTV, Network Measurement, Modeling.

\section{INTRODUCTION}

Recent tendencies show an increase of information pressure on Latvia. The society is exposed to the polarization of information. On the one hand, there is Russia, who does it by using government media resource. On the other hand, at the same time, correcting the situation of public opinion, Latvia and Europe.

The public opinion is used with some groups to destabilize targeted regions even further [1]. These groups have become masters of the "battle of narratives" - a struggle beyond the physical elements of a conflict in which the manipulation of the media, the use of the internet, and the integration of information operations with a strategic communication program are as important as weapons systems or even success on the battlefield [7].

The instruments used to determine the sign of the hybrid war are clear. They are based on the identification of signs. But the levels of invasion of the information are measured by outdated methods as sociological research. This method does not provide accurate data, since it is based just on a respondent answers, which can be known to be true. Sometimes the error exceeds more than $50 \%$. This is due to the emotional impact when the respondent does not want to disclose the real opinion [2]. Such researches do not provide operational data. They also do not show the dynamics of objective indicators. The perception of information differentiation is extremely low [3].

There is a need for a new instrument of determination and prediction of whole public opinion.
This instrument can be a model of public opinion changes.

The new instrument should consist from:

- profiling the audience with the possibility of excreting by separate groups / classes;

- identifying and predicting the speed of propagation of information;

- forecasting the depth of information;

- forecasting the possible public opinion;

- identify and anticipating the adoption of the reported information.

\section{METHODOLOGY OF THE RESEARCH}

Many technological advances were produced by trying to meet user needs and expectations in such a widespread media. For example, the large number of users that concurrently watch TV sparked the use of IP multicast in major Internet TV (IPTV) designs to save on the transmission cost [6].

IPTV television is one of the most successful platforms for filling model of relevant data, as anonym data are coming from the Middleware software system, what accurately shows the interaction of audience with the incoming information. IPTV System Architecture is shows on Figure 1. 


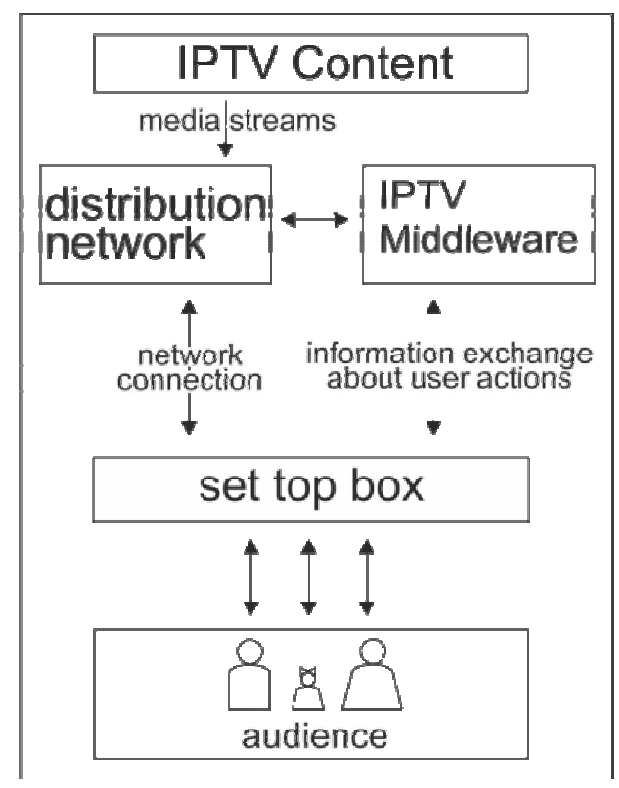

Fig. 1. IPTV System Architecture.

\section{A. Statistical module}

To protect the identity of the IPTV network subscribers, individual set top boxes were assigned a non-identifiable ID number for purposes of this research. The authors did not have access to subscriber's identity or address of individual set top boxes.

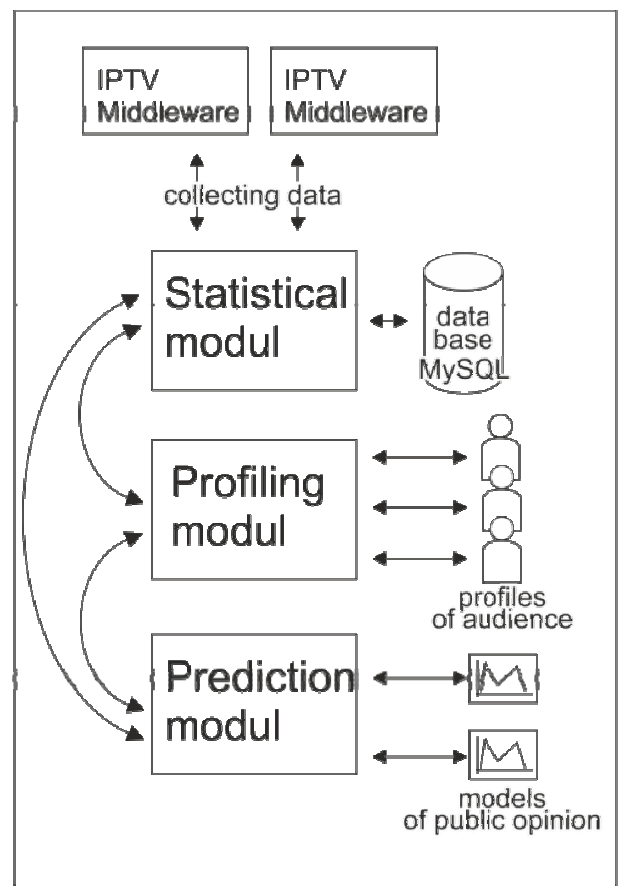

Fig. 2. The model of public opinion changes architecture.
The model of public opinion changes will consist of the following modules:

1. The module of collecting and storing of IPTV Middleware;

2. The module of processing and displaying the collected data;

3. Module of audience profiling;

4. Prediction module.

The model of public opinion changes architecture is shows on Figure 2.

IPTV Middleware displays and saves in the database of all the basic interaction of user with the interface. Middleware system is responsible for communication with every Set Top Box [4]. Then the data is written to the MySQL database where millions of records of watched TV channels and other user actions are placed [5].

Statistics system has internal scripts and a MySQL database which is responsible for storing all user actions data [5].

The main table in this database is table STAT which contains fields that are described in Table I.

Statistics system is collecting data from tree IPTV operator's Middleware. These operators work in all major cities and many districts of Latvia. This will give an opportunity to provide an accurate data for the whole country. The number of users covered by the statistics system data is over 3000. The number of analyzed channels is 120 . According to statistical standards it may give an error less than $2 \%$ [3].

The collected statistical data module (can be used as the output processing module). It will:

1. Identify and display statistics of popular TV channels.

2. Identify and display statistics of popularity of individual programs.

3. Show general statistics data for TV viewing.

4. Identify and display statistics of TV viewing among profiled audience (specific groups of viewers).

Model of processing and output of data uses the collected data to MySQL database. Processing and displaying takes place by using the written code in PHP. Code will run on the WEB server.

Module of profiling audience will separate a group of viewers by given attributes. Information based on the collected data can be:

1. The generalized (universal) profile of audience;

2. Allocated some of the most common profiles encountered of the auditory.

The profiling of the audience will be done by using tag (classes). Tags are included in EPG. EPG displays the name of the program and its genre. Using the statistics of viewed programs and classifying them by genre, each user can be classified as a profile. 
TABLE I

TABLE STAT IN STATISTICS DATABASE

\begin{tabular}{|l|l|l|}
\hline The name of field & The meaning of field & Type of the variable \\
\hline EVENT_ID & $\begin{array}{l}\text { This field signs what type of IPTV content is used for statistics - 1 } \\
\text { is for TV, } 2 \text { is for Catch-Up TV, } 3 \text { is for Time Shift }\end{array}$ & INTEGER \\
\hline CHANNEL_TAG & The name of TV channel & VARCHAR2 \\
\hline SUBSCRIBER_ID & Unique number for each subscriber & INTEGER \\
\hline DEVICE_ID & Unique number for each Set Top Box (IP address) & INTEGER \\
\hline TIMESTAMP & The time when TV content starts & DATETIME \\
\hline EPG & Electronic program guide information & VARCHAR2 \\
\hline EPG_GENRE & Genre of content & VARCHAR2 \\
\hline INSERT_DATE & Date and time when the record is inserted into MySQL database & DATETIME \\
\hline STB_STAT & Set top box status (1 - on, 0 - off) & INTEGER \\
\hline
\end{tabular}

\section{B. Profiling module}

Genres tables:

- News from Russia;

- News from Latvia;

- News from Ukraine;

- Other News;

- $\quad$ Science \& Technology;

- Educational program;

- Entertainment - female's;

- Entertainment - men's;

- Sport;

- Fight;

- Cinema- melodrama;

- Movie- drama;

- Movie- thriller/action;

- Comedy;

- Documentary;

- Children's/Family;

- Erotic.

Profile consists from points of each genre.

The main user profiles:

- Active viewer;

- Aggressive;

- News Consumer;

- Seeker of Knowledge;

- Cinema addict;

- Sports fan;

- Children;

- Housewife;

- Balanced profile.

For example, a client who spends about 12 hours watching TV, will be profiled as an "active audience" and viewer who generally watch mostly news programs, can be classified as "consumer news", and the client who watch mainly scientific programs - as "a seeker of knowledge".

Profiling module audience will also be set up as a WEB application that does not require working with it to install extra additional software.

\section{Prediction module}

One of the most important elements of the instrument will be the prediction possibility. The main task is to build a model of distribution, depth and perception of the proposed ideas. It will be the module of public opinion changes as shows on Figure 3.

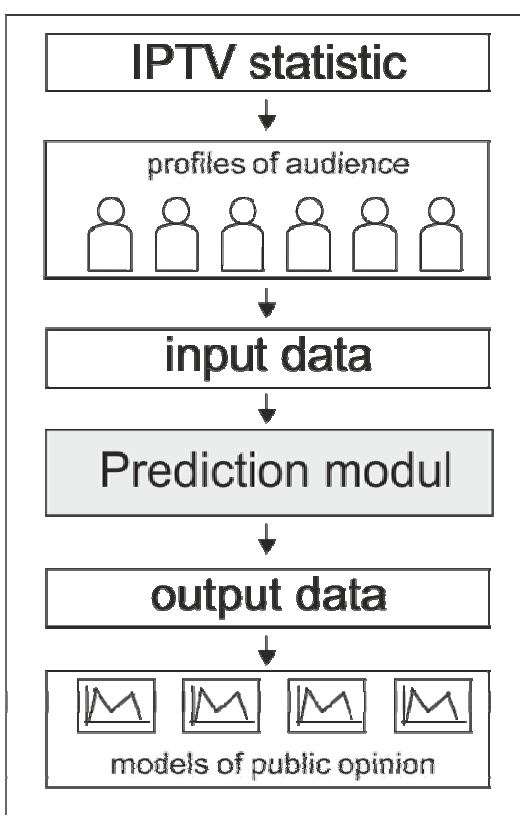

Fig. 3. The module of public opinion changes architecture. 
His foundation is a mathematical algorithm. Which, using a collected data from other modules and based on them, creates the requested model.

Predictions module makes model based on the data received from the other modules. Including in the model the following factors:

- Information events;

- Seasonality;

- Distance from political events;

- And others.

Information event - it is a fact that can influence public opinion. These may be for example, natural disaster, major holidays, loud statements of politicians, demonstrations and more.

Seasonality - this is time of year. Since the seasons can change a person's mood, it is necessary to explore and suggests in the model how the public perceives the different events depending on the time of year.

Political events, such as elections, the inauguration, the resignation, the fall can affect the mood of the public.

Considering the listed and other relevant factors, the instrument must predict how the public will react to a variety of international and local events, and how to develop this reaction.

Among the reactions can be identified:

- Taking;

- Not acceptance;

- Indifference;

- Disgust.

Each reaction will be expressed in percent, as all people do not react the same way. For each profile, the audience is the most common reaction.

\section{RESULTS AND DISCUSSION}

The results of the work will create a instrument that a variety of institutions will be able to apply it. These institutions may be:

- Television channels;

- Government agencies;

- Research organizations;

- Military forces;

- Others.

The instrument will not only accurately determine the current picture of situation, but also with high accuracy to make forecasts about the state of public opinion.

The instrument allows tracking the public mood and planning of media companies to inform the public.

Precise knowledge of the dynamics and trends of information dissemination through television can facilitate the work of government agencies related to public awareness. This will save money and improve the quality of work.

\section{SUMMARY}

At this moment, in Latvia, there are no similar methods used for determining public opinion, which significantly complicate the definition of a real picture of the happening processes in the society. Created model can help to solve this problem.

In the face of possible provocations and hybrid war, especially increases the relevance of the instrument.

The main problems in the future work may include:

- Lack of resources;

- Legal aspects;

- Lack of interest on the part of the organizations;

- Technical complexity.

Given the potential these challenges, it is necessary to involve additional experts to analyze the ideas contained in the article.

\section{REFERENCES}

[1.] C. WILLIAMSON, United States Army War College, Carlisle Barracks, 2009, pp.15-16.

[2.] MD LeCompte, JP Goetz, Problems of reliability and validity in ethnographic research, Review of educational research, 1982, pp.31-35.

[3.] L Jussim, Social perception and social reality: A reflectionconstruction model, Psychological review, 1991, pp. 54-73.

[4.] Y. J. Won, Mi-Jung Choi, Byung-Chul Park, J. W. Hong, Hee-Won Lee, Chan-Kyu Hwang, Jae-Hyoung Yoo, "EndUser IPTV Traffic Measurement of Residential Broadband Access Networks", IEEE Network Operations and Management Symposium Workshops, NOMS, 2008, pp. 95100.

[5.] A.Tanovic, I. Androulidakis, F. Orucevic, Analysis of IPTV Channels Watching Preferences in Bosnia and Herzegovina, ETASR - Engineering, Technology \& Applied Science Research Vol. 1, No. 5, 2011, pp. 105-113.

[6.] Cha, M., Rodriguez, P., Crowcroft, J., Moon, S., \& Amatriain, X., Watching a Nation Watch IPTV, IEEE Transactions on Multimedia, 2007, pp. 1672-1687.

[7.] U.S. Joint Forces Command, The Joint Operating Environment: Challenges and Implications for the Future Joint Force, 2009, pp.39. 